\title{
Comparative Study on the Intercultural Sensitivity of Japanese and Korean Nursing Students
}

Noriko Kuwano* and Michiru Kameya

Oita University of Nursing and Health Sciences, Megusuno, Oita-city, Oita, Japan

\begin{abstract}
Objective: The purpose of this study was to clarify the characteristics of Japanese and Korean nursing students' intercultural sensitivity, which is important when caring for culturally and linguistically diverse patients. By investigating nursing students' intercultural sensitivity across different countries with different value systems, we may grasp how nursing students can prepare for providing culturally competent, highquality care for patients with diverse backgrounds.
\end{abstract}

Methods: The participants were junior and senior nursing students at universities in Japan and Korea. The intercultural sensitivity scale (ISS) was administered to 379 students in both countries. The chi-square test and t-test were used to analyze differences in distribution and the mean scores for each country's students. This study was approved by a university institutional review board.

Results: The total number of collected questionnaires (ratio) was 251 (66.2\%), including 144 (90.6\%) from Japan and $107(48.6 \%)$ from Korea. With a maximum possible score of 120 , the average ISS of nursing students in Japan was $78.5( \pm 8.7)$ and in Korea was $81.5( \pm 10.4)$. After analyzing the mean score in each ISS subscale, significant differences were examined in "Interaction confidence" and "Interaction attentiveness" between the two countries. The nursing students who had interacted with non-Japanese/ non-Korean patients in clinical practice and those with better English-speaking ability had significantly higher ISS $(\mathrm{p}<.005)$ in both countries.

Discussion: In this study, the total ISS of Japanese nursing students was lower than that of Korean nursing students, and was significantly lower in two subscales. To enhance the intercultural sensitivity of nursing students, opportunities to practice cross-cultural communication with patients with diverse culturally and linguistically background for clinical and volunteer experiences may be needed.

\section{Introduction}

Intercultural sensitivity (IS) is defined as the ability to understand cultural differences positively [1], and is considered important when working with people from different cultures. IS is especially important for helping human service professionals including nurses to build better relationships with people from culturally diverse backgrounds [2]. As a result of increasing diversity, growing number of people with diverse background are visiting hospital settings in Japan and other Asian countries, where a historically mono-cultural society and has been progressively transitioning into more culturally diverse, and nurses as a front-line practitioner often find it difficult to fully understand their symptoms and conditions due to language barriers and different cultural background [3]. Previous studies have reported that Japanese nurses do not demonstrate their usual professional autonomy when caring for non-Japanese patients, and that IS affects their ability to demonstrate autonomy as a nursing professional [4].

Kılıçand Sevinç [6] reported that nursing students with higher IS have better communication skills and can enhance their IS through foreign language learning and the experience of living abroad. If IS can be improved through learning and having certain experiences, then Japanese nurses need to improve their IS starting from the time they are nursing students to provide the same level of care to both foreign and Japanese patients by exercising their autonomy. Enhancing IS of nurses and providing culturally sensitive care is one of the key factors in reducing inequalities in health care services [5]. However, at present, few studies on IS for nursing students in Japan and other Asian countries have been reported.

In the neighboring country of Korea, the number of foreign residents is on the rise because of the declining birthrate, aging population, and decreasing working population [7]. In South Korea, the government has been promoting medical tourism from an earlier stage compared with Japan, and this has had a positive and substantial economic effect. This situation may have influenced nursing students' experiences with foreign patients and IS. Therefore, in this study, we conducted a comparative survey of nursing students in Japan and South Korea to clarify the differences in and background factors of IS.

The purpose of this study was to clarify the differences in and background factors of IS among nursing students in Japan and Korea through a comparative study of Japanese and Korean nursing students.

\section{Research Method}

\section{Research design}

A descriptive cross-sectional design was used in this study.

\section{Participants}

The study participants were third- and fourth-year university nursing students in Japan and Korea in two institutions. A total of 379 students, 159 from Japan and 220 from Korea, participated in this study.

${ }^{*}$ Corresponding Author: Dr. Noriko Kuwano, Oita University of Nursing and Health Sciences, 2944-9 Megusuno, Oita-city, Oita 870-1201, Japan, Tel +81-97586-4487, Fax: +81-97-586-4388; E-mail: kuwano@oita-nhs.ac.jp

Citation: Kuwano N, Kameya M (2021) Comparative Study on the Intercultura Sensitivity of Japanese and Korean Nursing Students. Int J Nurs Clin Pract 8: 350. doi: https://doi.org/10.15344/2394-4978/2021/350

Copyright: (C) 2021 Kuwano et al. This is an open-access article distributed under the terms of the Creative Commons Attribution License, which permits unrestricted use, distribution, and reproduction in any medium, provided the original author and source are credited. 


\section{Data collection}

Purposive sampling was used to collect data between June 1 and August 10, 2018. A survey was conducted using a self-administered anonymous questionnaire. The questionnaire consisted of 13 items, including attributes based on previous studies [4-6] and 24 items from the Intercultural Sensitivity Scale (ISS) [1,8]. For the 13 attributes, an English version was created first; then, Japanese and Korean versions were created by Japanese and Korean researchers, respectively, based on the English version. The consistency of the Japanese and Korean versions was checked by the Korean and Japanese researchers in terms of English and with the assistance of a Japanese graduate student who was fluent in Korean, and then back-translated into English to ensure the accuracy and cultural appropriateness of the translation. For the ISS, we used the Japanese version [4] and the Korean version [9]. This scale consists of five factors: interaction engagement (7 items), respect for cultural differences (6 items), interaction confidence (5 items), interaction enjoyment ( 3 items), and interaction attentiveness ( 3 items). Each item was rated on a 5-point Likert-type scale ranging from strongly disagree (scored as 1 ) to strongly agree (scored as 5). The total possible IS score was 120. The Cronbach's alpha of the scale was reported in original English version as 0.88 [8].

At the Japanese university, the co-researcher, who had no conflict of interest with the research participants, directly explained the survey contents to the participants orally and in writing, and then distributed the questionnaires during a break after the lectures. The researchers set up collection boxes at appropriate locations on campus and asked the participants to place the questionnaires in sealed envelopes and drop them in the collection boxes. The collection boxes were sealed so that only the researchers could collect and access the questionnaires after they had been dropped off. At the Korean university, the questionnaires were distributed and collected through the person in charge at the reception desk.

\section{Analysis methods}

The ISS was scored and tabulated for all 24 items and five subscales based on a 5-point scale (from 1 for "completely disagree" to 5 for "very much agree"). Microsoft Excel and IBM SPSS Statistics 22.0 (Tokyo, Japan) were used for tabulation and analysis. The significance level was set at $\mathrm{p}<0.05$.

\section{Ethical considerations}

A request letter was attached to the questionnaire when it was distributed to the participants. The request letter described the purpose of the study, that participation was voluntary, that they could discontinue participation at any time without penalty, that the study was not related to academic performance in any way, that the data would not be used for any purpose other than research, that the data would be kept in a locked storage room in the laboratory and shredded and destroyed at the end of the study, that their anonymity would be protected, that the analysis would be coded so that no individual or university could be identified, and that the results of the study would be made public in an anonymous manner. Responding to the questionnaire was taken as consent. This study was approved by the Research Ethics and Safety Committee of Oita University of Nursing and Health Sciences (approval date May 25, 2018, approval No.: 18-23).

\section{Results}

\section{Demographics and backgrounds of the participants in Japan and Korea}

The number of questionnaires distributed was 159 in Japan and 220 in Korea, and the number (percentage) of questionnaires collected was 107 (48.6\%) in Korea and 144 (90.6\%) in Japan. Table 1 shows the results regarding the attributes of the participants. No significant differences in the distribution of each item were observed between Japan and Korea in terms of sex and grade.

A significant difference was found in the distribution of frequencies between Japan and Korea for the following items: 85 (59.0\%) and $86(80.4 \%)$ respondents in Japan and Korea, respectively, answered "Yes" for overseas travel experience, 115 (79.9\%) and 54 (50.5\%) answered "Yes" for the experience of interacting with foreigners, 110 (76.4\%) and 98 (91.6\%) answered "Yes" for the experience of receiving multicultural education, 13 (9.0\%) and 56 (52.3\%) answered "Yes" for the experience of working with foreign patients in practical training, and $121(84.0 \%)$ and 104 (97.2\%) answered "Yes" for opportunities to interact with foreign patients when working as a nurse in the future.

Regarding the ability to speak English (as a foreign language), 53 $(36.8 \%)$ of the respondents in Japan answered that they could not speak English very well, while 57 (53.3\%) of the respondents in Korea answered that they could speak English in simple conversations.

\section{Sensitivity to different cultures among Japanese and Korean nursing students}

The mean \pm standard deviation total ISS scores were $78.55 \pm 8.7$ for Japanese nursing students and $81.52 \pm 10.4$ for Korean nursing students. The mean subscale scores are shown in Table 2. The mean scores for Total $(\mathrm{t}=2.379, \mathrm{p}=.018)$, Interaction Confidence $(\mathrm{t}=6.847, \mathrm{p}<.001)$, and Interaction Attentiveness $(\mathrm{t}=2.710, \mathrm{p}=.007)$ were significantly higher in Korean than in Japanese nursing students (Table 2).

\section{Interaction experience with foreigners and ISS}

When the mean ISS scores were compared based on whether the respondents had experience interacting with foreigners (by country), Japanese nursing students showed significantly higher mean scores for Interaction Confidence $(\mathrm{t}=2.450, \mathrm{p}=.017)$ and Interaction Attentiveness ( $\mathrm{t}=1.999, \mathrm{p}=.049)$, while Korean nursing students showed significantly higher mean scores for Total $(\mathrm{t}=2.108, \mathrm{p}=.038)$; in both cases, all students in the group with interaction experience had higher mean scores (Table 3).

When the mean ISS scores were compared based on whether the participants had experience interacting with foreign patients in their practice (by country), Japanese nursing students showed a significant difference in Interaction Enjoyment $(t=2.300, p=.037)$, while Korean nursing students showed a significant difference in Total $(t=2.631$, $\mathrm{p}=.010)$, Interaction Engagement $(\mathrm{t}=2.476, \mathrm{p}=.015)$, and Interaction Attentiveness ( $\mathrm{t}=2.113, \mathrm{p}=.037)$; all had higher mean scores in the group that had experience working with foreign patients (Table 4).

\section{English-speaking ability and ISS}

With regard to English-speaking ability, we analyzed the participants' responses on a 6-point scale (from 1, "very fluent" to 
Citation: Kuwano N, Kameya M (2021) Comparative Study on the Intercultural Sensitivity of Japanese and Korean Nursing Students. Int J Nurs Clin Pract 8: 350. doi: https://doi.org/10.15344/2394-4978/2021/350

Page 3 of 6

\begin{tabular}{|c|c|c|c|c|c|c|}
\hline \multirow[t]{2}{*}{ Characteristics } & \multirow[t]{2}{*}{ Categories } & \multicolumn{2}{|l|}{$\begin{array}{l}\text { Japan } \\
\mathrm{n}=144\end{array}$} & \multicolumn{3}{|l|}{$\begin{array}{l}\text { Korea } \\
n=107\end{array}$} \\
\hline & & $\mathrm{N}(\%)$ & $\operatorname{Mean}( \pm \mathrm{SD})$ (Range) & $\mathrm{N}(\%)$ & Mean $( \pm S D)$ (Range) & $\chi^{2}$ \\
\hline Age & & & $20.93( \pm 0.82)(20-24)$ & & $21.54( \pm 1.34)(20-26)$ & \\
\hline \multirow[t]{3}{*}{ Gender } & & & & & & 0.824 \\
\hline & Male & $12(8.3)$ & & $10(9.3)$ & & \\
\hline & Female & $132(91.7)$ & & $97(90.7)$ & & \\
\hline \multirow[t]{3}{*}{ Grade } & & & & & & 0.524 \\
\hline & 3 & $79(54.9)$ & & $54(50.5)$ & & \\
\hline & 4 & $65(45.1)$ & & $53(49.5)$ & & \\
\hline \multicolumn{7}{|l|}{ Religion } \\
\hline & Protestant & $1(0.7)$ & & $15(14.0)$ & & \\
\hline & Catholic & $1(0.7)$ & & $4(3.7)$ & & \\
\hline & Buddhism & $58(40.3)$ & & $14(13.1)$ & & \\
\hline & Islam & $0(0.0)$ & & $0(0.0)$ & & \\
\hline & Nothing & $75(52.1)$ & & $73(68.3)$ & & \\
\hline & Others & $2(1.4)$ & & $1(0.9)$ & & \\
\hline & No answer & $7(4.9)$ & & $0(0.0)$ & & \\
\hline \multicolumn{2}{|c|}{ Experience of visiting abroad } & & & & & $\mathrm{p}<0.001^{\star}$ \\
\hline & Yes & $85(59.0)$ & & $86(80.4)$ & & \\
\hline & No & $59(41.0)$ & & 21(19.6) & & \\
\hline \multicolumn{7}{|c|}{ Ability to speak foreign languages } \\
\hline & Very Fluent & $2(1.4)$ & & $1(0.9)$ & & \\
\hline & Fluent & $0(0.0)$ & & $5(4.7)$ & & \\
\hline & able to speak simple conversation & $31(21.5)$ & & $57(53.3)$ & & \\
\hline & Poor & $53(36.8)$ & & $27(25.2)$ & & \\
\hline & Very poor & $52(36.1)$ & & $14(13.1)$ & & \\
\hline & Unable to speak & $6(4.2)$ & & $3(2.8)$ & & \\
\hline \multicolumn{2}{|c|}{ Experience to interact with foreigners } & & & & & $\mathrm{p}<0.001^{\star}$ \\
\hline & Yes & $115(79.9)$ & & $54(50.5)$ & & \\
\hline & No & $29(20.1)$ & & $52(48.6)$ & & \\
\hline & No answer & $0(0.0)$ & & $1(0.9)$ & & \\
\hline \multirow[t]{4}{*}{ Foreign friends } & & & & & & $0.045^{*}$ \\
\hline & Yes & $46(31.9)$ & & $22(20.6)$ & & \\
\hline & No & $97(67.4)$ & & $85(79.4)$ & & \\
\hline & No answer & $1(0.7)$ & & $0(0.0)$ & & \\
\hline \multicolumn{2}{|c|}{ Opportunity to learn cultural diversity } & & & & & $0.011^{*}$ \\
\hline & Yes & $110(76.4)$ & & $98(91.6)$ & & \\
\hline & No & $28(19.4)$ & & $9(8.4)$ & & \\
\hline & No answer & $6(4.2)$ & & $0(0.0)$ & & \\
\hline \multicolumn{2}{|c|}{ Opportunity to learn international nursing } & & & & & $\mathrm{p}<0.001^{*}$ \\
\hline & Yes & 141(97.9) & & $28(26.2)$ & & \\
\hline & No & $2(1.4)$ & & $77(72.0)$ & & \\
\hline & No answer & $1(0.7)$ & & $2(1.9)$ & & \\
\hline \multicolumn{4}{|c|}{ experience to interact with foreign patients during the clinical practicum } & & & $\mathrm{p}<0.001^{*}$ \\
\hline & Yes & $13(9.0)$ & & $56(52.3)$ & & \\
\hline & No & $131(91.0)$ & & $49(45.8)$ & & \\
\hline & No answer & $0(0.0)$ & & 2(1.9) & & \\
\hline \multicolumn{7}{|l|}{ Career goal } \\
\hline & Registered Nurse & $108(75.0)$ & & $91(85.0)$ & & \\
\hline & Midwife & $13(9.0)$ & & $0(0.0)$ & & \\
\hline & Public Health Nurse & $7(4.9)$ & & $6(5.7)$ & & \\
\hline & School Nurse & $14(9.7)$ & & $1(0.9)$ & & \\
\hline & others & $2(1.4)$ & & $9(8.4)$ & & \\
\hline \multicolumn{5}{|c|}{ A chance to provide care for foreign patients in the future at your workplace as a nurse } & & $0.001^{*}$ \\
\hline & Yes & $121(84.0)$ & & $104(97.2)$ & & \\
\hline & No & $23(16.0)$ & & $3(2.8)$ & & \\
\hline
\end{tabular}


Citation: Kuwano N, Kameya M (2021) Comparative Study on the Intercultural Sensitivity of Japanese and Korean Nursing Students. Int J Nurs Clin Pract 8: 350. doi: https://doi.org/10.15344/2394-4978/2021/350

\begin{tabular}{|l|l|l|l|l|l|}
\hline & Category Items & $\begin{array}{l}\text { Japan } \\
(\mathrm{n}=144) \\
\mathrm{M} \pm \mathrm{SD}\end{array}$ & $\begin{array}{l}\text { Korea } \\
(\mathrm{n}=107) \\
\mathrm{M} \pm \mathrm{SD}\end{array}$ & $t$ & $p$ \\
\hline 1. & Interaction Engagement & $24.05 \pm 3.28$ & $23.09 \pm 4.16$ & -1.962 & 0.051 \\
2. & Respect of Cultural Defferences & $23.12 \pm 3.03$ & $23.71 \pm 3.68$ & 1.357 & 0.176 \\
3. & Interaction Confidence & $11.50 \pm 3.11$ & $14.36 \pm 3.37$ & 6.847 & $\mathrm{p}<0.001^{*}$ \\
4. & Interaction Enjoyment & $9.97 \pm 1.91$ & $9.82 \pm 1.59$ & -0.675 & 0.500 \\
5. & Interaction Attentiveness & $9.91 \pm 1.70$ & $10.54 \pm 1.91$ & 2.710 & $0.007^{*}$ \\
& Total & $78.55 \pm 8.78$ & $81.52 \pm 10.48$ & 2.379 & $0.018^{*}$ \\
\hline
\end{tabular}

Table 2: Intercultural sensitivity of Japanese and Korean nursing students.

$\mathrm{N}=251,{ }^{*} \mathrm{p}<.05$

\begin{tabular}{|c|c|c|c|c|c|c|c|}
\hline & \multirow[t]{3}{*}{ Items } & \multicolumn{2}{|c|}{ Japan $(n=144)$} & \multirow[t]{3}{*}{$p$} & \multicolumn{2}{|c|}{ Korea $(n=106)$} & \multirow[t]{3}{*}{$p$} \\
\hline & & $\operatorname{Yes}(\mathrm{n}=115)$ & $\mathrm{No}(\mathrm{n}=29)$ & & Yes $(\mathrm{n}=54)$ & $\mathrm{No}(\mathrm{n}=52)$ & \\
\hline & & \multicolumn{2}{|c|}{$\mathrm{M} \pm \mathrm{SD}$} & & \multicolumn{2}{|c|}{$\mathrm{M} \pm \mathrm{SD}$} & \\
\hline 1. & Interaction Engagement & $24.24 \pm 3.24$ & $23.28 \pm 3.41$ & 0.175 & $23.81 \pm 4.74$ & $22.44 \pm 3.33$ & 0.087 \\
\hline 2. & Respect of Cultural Defferences & $23.05 \pm 3.01$ & $23.38 \pm 3.14$ & 0.616 & $24.11 \pm 3.93$ & $23.40 \pm 3.34$ & 0.320 \\
\hline 3. & Interaction Confidence & $11.77 \pm 3.22$ & $10.45 \pm 2.39$ & $0.017^{*}$ & $14.94 \pm 3.53$ & $13.77 \pm 3.16$ & 0.074 \\
\hline 4. & Interaction Enjoyment & $9.93 \pm 1.93$ & $10.14 \pm 1.86$ & 0.598 & $10.06 \pm 1.48$ & $9.56 \pm 1.68$ & 0.110 \\
\hline 5. & Interaction Attentiveness & $10.01 \pm 1.83$ & $9.52 \pm 0.94$ & $0.049^{\star}$ & $10.78 \pm 1.93$ & $10.35 \pm 1.86$ & 0.246 \\
\hline & Total & $79.00 \pm 8.80$ & $76.76 \pm 8.64$ & 0.220 & $83.70 \pm 11.95$ & $79.52 \pm 8.20$ & $0.038^{\star}$ \\
\hline
\end{tabular}

Table 3: Comparison of ISS between Yes and No group if students experienced interaction with foreigners in Japan and Korea. $\mathrm{N}=250,{ }^{*} \mathrm{p}<.05$

※ One Korean participants was excluded because of no answer for the question about experience to interact with foreigners.

\begin{tabular}{|c|c|c|c|c|c|c|c|}
\hline & \multirow[t]{3}{*}{ Items } & \multicolumn{2}{|c|}{ Japan $(n=144)$} & \multirow[t]{3}{*}{$p$} & \multicolumn{2}{|c|}{ Korea $(n=105)$} & \multirow[t]{3}{*}{$p$} \\
\hline & & $\operatorname{Yes}(\mathrm{n}=13)$ & $\mathrm{No}(\mathrm{n}=131)$ & & $\operatorname{Yes}(\mathrm{n}=56)$ & $\mathrm{No}(\mathrm{n}=49)$ & \\
\hline & & \multicolumn{2}{|c|}{$\mathrm{M} \pm \mathrm{SD}$} & & \multicolumn{2}{|c|}{$\mathrm{M} \pm \mathrm{SD}$} & \\
\hline 1. & Interaction Engagement & $24.92 \pm 4.62$ & $23.96 \pm 3.13$ & 0.477 & $24.05 \pm 4.37$ & $22.10 \pm 3.70$ & $0.015^{*}$ \\
\hline 2. & Respect of Cultural Defferences & $23.31 \pm 3.94$ & $23.10 \pm 2.94$ & 0.856 & $24.34 \pm 3.92$ & $23.06 \pm 3.34$ & 0.075 \\
\hline 3. & Interaction Confidence & $13.15 \pm 3.55$ & $11.34 \pm 3.03$ & 0.097 & $14.77 \pm 3.29$ & $13.98 \pm 3.46$ & 0.237 \\
\hline 4. & Interaction Enjoyment & $11.23 \pm 2.08$ & $9.85 \pm 1.85$ & $0.037^{*}$ & $10.02 \pm 1.56$ & $9.65 \pm 1.62$ & 0.246 \\
\hline 5. & Interaction Attentiveness & $9.85 \pm 2.19$ & $9.92 \pm 1.66$ & 0.913 & $10.89 \pm 1.99$ & $10.12 \pm 1.74$ & $0.037^{*}$ \\
\hline & Total & $82.46 \pm 11.85$ & $78.16 \pm 8.38$ & 0.223 & $84.07 \pm 11.67$ & $78.92 \pm 8.28$ & $0.010^{*}$ \\
\hline
\end{tabular}

Table 4: Comparison of ISS between Yes and No group if students experienced interaction with foreign patients in clinical practice in Japan and Korea.

$\mathrm{N}=249,{ }^{*} \mathrm{p}<.05$

※ Two Korean participants were excluded because of no answer for the question about experience to interact with foreign patients.

\begin{tabular}{|c|c|c|c|c|c|c|c|}
\hline & \multirow[t]{3}{*}{ Items } & \multicolumn{2}{|c|}{$\operatorname{Japan}(\mathrm{n}=144)$} & \multirow[t]{3}{*}{$p$} & \multicolumn{2}{|c|}{ Korea $(n=107)$} & \multirow[t]{3}{*}{$p$} \\
\hline & & $\operatorname{Yes}(\mathrm{n}=33)$ & $\operatorname{No}(n=111)$ & & $\operatorname{Yes}(n=63)$ & $\operatorname{No}(n=44)$ & \\
\hline & & \multicolumn{2}{|c|}{$\mathrm{M} \pm \mathrm{SD}$} & & \multicolumn{2}{|c|}{$\mathrm{M} \pm \mathrm{SD}$} & \\
\hline 1. & Interaction Engagement & $25.94 \pm 2.80$ & $23.49 \pm 3.22$ & $\mathrm{p}<0.001^{\star}$ & $24.13 \pm 4.36$ & $21.61 \pm 3.38$ & $0.001^{\star}$ \\
\hline 2. & Respect of Cultural Defferences & $24.24 \pm 3.59$ & $22.78 \pm 2.77$ & $0.037^{\star}$ & $23.81 \pm 3.89$ & $23.57 \pm 3.38$ & 0.734 \\
\hline 3. & Interaction Confidence & $13.09 \pm 3.60$ & $11.03 \pm 2.79$ & $0.004^{*}$ & $15.14 \pm 3.05$ & $13.23 \pm 3.53$ & $0.005^{\star}$ \\
\hline 4. & Interaction Enjoyment & $10.94 \pm 1.96$ & $9.68 \pm 1.80$ & $0.002^{*}$ & $9.81 \pm 1.62$ & $9.84 \pm 1.56$ & 0.920 \\
\hline 5. & Interaction Attentiveness & $9.94 \pm 2.17$ & $9.90 \pm 1.54$ & 0.925 & $10.59 \pm 1.96$ & $10.48 \pm 1.86$ & 0.769 \\
\hline & Total & $84.15 \pm 8.94$ & $76.88 \pm 8.05$ & $\mathrm{p}<0.001^{*}$ & $83.48 \pm 11.15$ & $78.73 \pm 8.83$ & $0.016^{*}$ \\
\hline
\end{tabular}

Table 5: Comparison of ISS between Yes and No group if students can speak foreign languages in Japan and Korea.

$\mathrm{N}=251,{ }^{*} \mathrm{p}<.05$ 
6, "not fluent at all") and classified them into two groups: those with 1-3 points were considered "fluent" and those with 4-6 points were considered "not fluent". When the mean ISS scores were compared between the two groups (per country) in regard to English-speaking ability, Japanese nursing students scored higher for Total $(t=4.191$, $\mathrm{p}<.001)$, Interaction Engagement $(\mathrm{t}=4.257, \mathrm{p}<.001)$, and Respect for Cultural Differences $(\mathrm{t}=2.148, \mathrm{p}=.037)$; Interaction Confidence $(t=3.026, p=.004)$ and Interaction Enjoyment $(t=3.275, p=.002)$ were significantly different. In Korea, significant differences were found for Total $(t=2.453, p=.016)$, Interaction Engagement $(t=3.352, p=.001)$, and Interaction Confidence $(\mathrm{t}=2.918, \mathrm{p}=.005)$, and the mean score was higher in the group that answered that they could speak in both Japanese and Korean (Table 5).

No significant differences in mean ISS scores were seen between those who had traveled abroad and those who had not, those who had the opportunity to receive multicultural education and those who had not, and those who thought they would have the opportunity to work with foreign patients in the future when they worked as nurses and those who thought they would not, in both countries.

\section{Discussion}

\section{Sensitivity to different cultures among Japanese and Korean nursing students}

When the total ISS scores were compared between Japan and Korea, the total mean score for the Korean nursing students was significantly higher than that of the Japanese nursing students, suggesting that Korean nursing students are more culturally sensitive. Considering each subscale, the mean scores for Interaction Confidence and Interaction Attentiveness were significantly higher for Korean than for Japanese nursing students, suggesting that Korean nursing students are able to interact with foreigners with more confidence and understand events that occur as a result of differences in cultural backgrounds than are Japanese nursing students. Korean nursing students are therefore considered to be more confident than their Japanese counterparts when interacting with foreigners and more willing to understand events that occur because of differences in cultural backgrounds. IS is important in the areas of education and intercultural communication, especially in the medical profession $[10,11]$. Cultivating and enhancing the IS of nursing students, who will become nursing professionals in the future, is likely to have a positive impact on their ability to build relationships with patients from various backgrounds in clinical practice.

\section{Influence of the experience of interacting with foreigners and working with foreign patients on IS}

In this study, the mean total ISS score was higher in the group with experience interacting with foreigners in both Japan and Korea. In Japan, the mean score of the group with experience interacting with foreigners was significantly higher in Interaction Confidence and Interaction Attentiveness, while in Korea, a significant difference was found in the total mean score. In addition, the mean ISS score was significantly higher in both Japan and Korea for the group that answered "Yes" to the question "Have you had experience interacting with foreign patients in practice" than for the group that answered "No"; these results suggest that the experience of interacting with foreigners has an impact on IS. Göl \& Özum mentioned that the total score of Intercultural Sensitivity Scale was higher among those nursing students who had encounters with people with different cultural backgrounds for any reason and those who wanted to work abroad [12]. Ayse, Fatma \& Sebahat, and Toda \& Maru also reported that interactions with people from different cultures contribute to the improvement of IS, suggesting the necessity of increasing opportunities for intercultural exchange in the curriculum $[11,13,14]$.

In this study, no significant difference was found in the mean ISS score between the two groups for whether they would have opportunities to interact with foreign patients when working as a nurse in the future. However, a significant difference was seen in the distribution of frequencies between the two groups in Japan and Korea, and more than $97 \%$ of the students in Korea assumed that they would be providing nursing care for foreign patients in the future; this may be largely due to differences in social backgrounds. Ohnishi, Tanaka, Nishihara, lee, GO, \& Morifuji found that Korean nursing students, regardless of their level of interest or international exchange experience, were aware of the need to provide medical health care services to foreigners, while majority of Japanese nursing students were not interested in this issue [15]. The proportion of foreigners in Korea has been increasing rapidly over the past decade, and as a result, it is likely that foreigners in Korea have been exposed to healthcare issues through not only formal educational institutions, but also the media and general sources [15]. In this study as well, more than 50\% of the Korean students answered that they had experience working with foreign patients during their practical training, compared with less than $10 \%$ of the Japanese students. It can therefore be inferred that there are fewer opportunities to interact with foreign patients in clinical settings at general hospitals in Japan than in Korea, and this may be why Japanese students tend to limit their image of nursing to Japanese patients and think of nursing as being limited to Japanese people. By experiencing many opportunities to provide nursing care to foreigners while they are still nursing students, as is the case in Korea, Japanese students may be able to imagine the possibility of future relationships with foreigners and increase their readiness more concretely. As the number of non-Japanese patients is expected to increase in the future, training that prepares students for situations in which foreigners are the target, such as having opportunities to interact with foreigners in clinical practice and conducting exercises with simulated foreign patients, needs to be incorporated into undergraduate education.

\section{Influence of English-speaking ability on IS among nursing students}

In this study, the mean scores for Total, Interaction Engagement, and Interaction Confidence were significantly higher in the group that answered "Yes" to English-speaking ability than in the group that answered "No" in both Japan and Korea. It is thought that having a high proficiency in a foreign language is linked to confidence in cross-cultural communication and building good relationships with intercultural partners. Language is a major factor in communication, so it is predictable that language influences IS. According to Meydanlioglu, Arikan, and Gozum, knowing the language of another culture can lead to a better understanding of the culture and enhance IS among students [5]. In this study, Japanese students showed a significant difference in total and mean ISS scores for four of the five subscales, indicating that the ability to speak English has an impact on IS. Kato mentioned that Japanese nursing students do not usually spend time learning English because of the overcrowded curriculum [16].However, one of the relatively direct consequences of learning more than one language is to become familiar with more than one culture in a progressive way, or at least to develop an awareness of such multiculturalism [17]. Successful language learning will change 
the way people look at themselves, their identity, and their culture, and this is because successful language learning also increases selfawareness and cultural awareness [17]. In this perspective, enhancing nursing education with programs that improve the students' foreign language ability will help them to successfully manage cultural differences and provide culturally appropriate care in their nursing practice.

Nurses must build relationships with patients and respond to their needs. When providing care to foreign patients, high language proficiency not only facilitates communication, but also enables the nurse to understand the culture of the foreign patient and respond to their needs as quickly as possible. Although foreign patients are not necessarily English speakers, their willingness to and attitudes toward learning English as a foreign language may have an impact on the improvement of IS. The importance of effective verbal and non-verbal cross-cultural communication cannot be overemphasized as it is the basis of establishing trust and obtaining accurate health assessments and providing instructions [18]. Learning a foreign language may be one of the measures to improve IS in order to provide safe and secure nursing care to foreign patients.

\section{Conclusion}

In this study, the mean ISS score was higher for Korean than for Japanese nursing students. In both countries, students who had experience interacting with foreigners or with foreign patients in clinical practice had higher IS compared with other students, suggesting that the experience of interacting with foreigners may have an impact on IS. More than half of the Korean students had experienced interactions with foreigners in clinical practice, compared with less than $10 \%$ of the Japanese students. Moreover, in both Japan and Korea, students who responded that they had the ability to speak English were more culturally sensitive. Increasing IS among nursing students is thought to lead to the provision of higher quality nursing care, regardless of the cultural background of the patient. These findings suggest the necessity of increasing opportunities to interact with individuals who have different cultural backgrounds through clinical practice and activities both on and off campus.

\section{Study Limitations}

This study did have some limitations. First, the number of survey areas and facilities in Japan and Korea were limited, and only a small number of participants were analyzed, so caution is warranted when generalizing the IS of Japanese and Korean nursing students to different cultures based on the results of this study. To confirm the results of this study, it will be necessary to expand the study area and numbers of target facilities and participants in a future study.

\section{Competing Interests}

The authors declare that they have no competing interests.

\section{Author's Contributions}

Dr. Noriko Kuwano: the conception and design of the study, acquisition of data, analysis and interpretation of data, drafting the article and revising it critically for important intellectual content, final approval of the version of be submitted.

Michiru Kameya: The conception and design of the study, acquisition of data, analysis and interpretation of data, drafting the article.

\section{Acknowledgments}

We would like to thank all the nursing students in Japan and Korea who took part in this study. We would also like to express our sincere gratitude to Dr. Choe Myoung Ae, Emeritus Professor of Seoul National University and Dr. Young Hui Hwang, University of Ulsan, college of Medicine, Department of Nursing for their support for collecting data in Korea and guidance during the research.

\section{References}

1. Chen GM, Starosta WJ (1997) A review of the concept of intercultura sensitivity. Human Communication 1: 1-16.

2. Suzuki Y, Saito S (2016) Development of Intercultural Sensitivity scale in Japanese. Bulletin of Graduate School of Human Development and Environment. Kobe University 9: 39-44.

3. Inoue $Y$, Hagimura $T$, Yoshikawa $M$ (2010) Ikoku de nyuin to nattatkanja no shinri wo shiru (Mental state of the patient who was hospitalized in a foreign country). The Journal of Chitose City Hospital 6: 51-53.

4. Kuwano N, Fukuda H, Murashima S (2015) Factors Affecting Professional Autonomy of Japanese Nurses Caring for Culturally and Linguistically Diverse Patients in a Hospital Setting in Japan. J Transcult Nurs 27: 567-573.

5. Meydanlioglu A, Arikan F, Gozum S (2015) Cultural sensitivity levels of university students receiving education in health disciplines. Adv Health $\mathrm{Sci}$ Educ Theory Pract 20: 1195-1204.

6. Kılıç SP, Sevinç S (2018) The Relationship between Cultural Sensitivity and Assertiveness in Nursing Students from Turkey. J Transcult Nurs 29: 379-386.

7. Korean Statistical Information Service (2020) Statistical data base.

8. Chen GM, Starosta WJ (2000) The development and validation of the intercultural communication sensitivity scale. Human Communication 3: $1-15$.

9. Roh SZ (2014) A Study on the Factors Affecting the Intercultural Sensitivity of Middle and High School Students in Korea. Science and Technology Letters 47: 266-269.

10. Hatice S, Ozum E, Temel AB (2017) Cultural Sensitivity and Related Factors among Nurse Educators in Turkey. Int J Caring Sci 10: 1374-1381.

11. Ayse M, Fatma A, Sebahat G (2015) Cultural sensitivity levels of university students receiving education in health disciplines. Health Sci Educ 20: 11951204.

12. Göl I, Özum E (2018) Association between cultural intelligence and cultural sensitivity in nursing students: A cross-sectional descriptive study. Collegian 26: 485-491.

13. Toda T, Maru M (2018) Changes of Cultural Sensitivities of Pre and Post of the Study Abroad Program. Konan Women's University Academic Repository 12: 37-44.

14. Toda T, Maru M (2020) Changes of Cultural Sensitivities of Pre and Post of the Study Abroad Program: 2nd Report. Konan Women's University Academic Repository 14: 11-18.

15. Ohnishi M, Tanaka J, Nishihara M, Lee JY, Num GH, et al. (2017) A study on undergraduate nursing students' perspective of healthcare provision for foreign nationals: a survey on Japanese and Korean university students. Health Science Research 30: 1-10.

16. Kato Y (2020) The Current Situation and Challenges of Short-term Study Overseas Training Programs at Faculties of Nursing. Ishikawa Journal of Nursing 17: 1-10.

17. Chiesa B (2015) Chapter 1. In: Languages in a Global World: Learning for better Cultural Understanding, Japanese language edition. Paris and Akashi Shoten Co., Ltd., Tokyo.

18. Purnell L (2018) Cross Cultural Communication: Verbal and Non-Verbal Communication, Interpretation and Translation. In: Douglas M., Pacquiao D., Purnell L. (eds) Global Applications of Culturally Competent Health Care: Guidelines for Practice. Springer, Cham. 